\title{
MEMAKSIMALKAN KEUNTUNGAN HARIAN PADA INDUSTRI RUMAHAN "NANDA JAYA" DENGAN PENERAPAN METODE SIMPLEKS
}

\author{
Maximizing Daily Profits in Home Industry "NANDA JAYA" \\ by Apply the Simplex Method
}

\author{
Lukas Susanto* \\ Program Studi Pendidikan Matematika, FKIP, Universitas PGRI Madiun. \\ Jln. Setiabudi No. 58, Madiun 63118, Jawa Timur, Indonesia. \\ e-mail:*lks.ssnt@gmail.com \\ Corresponding author*
}

\begin{abstract}
Abstrak
Industri rumahan "Nanda Jaya", kesehariannya memproduksi Kripik Pisang, Kripik Singkong, dan Kripik Tempe. Dari observasi pendahuluan diperoleh informasi bahwa dalam penentuan komposisi banyak unit untuk tiap jenis kripik yang diproduksi, dan penentuan harga jual produk per unit, dilakukan atas dasar pengalaman selama menjalankan usahanya, jadi belum ada suatu cara yang optimal untuk menentukannya. Dengan kondisi ini, perolehan keuntungan perusahaan perlu dilihat kembali apakah sudah optimal atau belum. Tujuan penelitian ini adalah menentukan banyak unit produksi pada setiap jenis kripik, agar memperoleh keuntungan yang maksimal dan juga menentukan efisiensi yang terjadi dalam pemanfaatan sumber daya biaya dan waktu. Pengumpulan data dilakukan dengan observasi dan wawancara. Model matematika dari permasalahan penelitian merupakan permasalahan program linear dengan tiga variabel yang bisa diselesaikan dengan metode simpleks. Dari hasil analisis data, disimpulkan supaya keuntungan maksimal bisa diperoleh, perusahaan harus memproduksi Kripik Pisang 74 unit, Kripik Singkong 161 unit dan Kripik Tempe tidak diproduksi. Keuntungan maksimumnya Rp. 285,387,- (sebelumnya Rp. 247.000,), Modal Produksi berkurang menjadi Rp. 889.613,-- (sebelumnya Rp. 928.000,-), sedangkan total waktu yang tersedia habis terpakai.
\end{abstract}

Kata Kunci : Memaksimalkan Keuntungan, Banyak Unit produksi, Metode Simpleks

\begin{abstract}
The home industry "Nanda Jaya" produces banana chips, cassava chips and tempe chips daily. From preliminary observations, information is obtained that in determining the composition of the number of units for each type of chips produced, and determining the selling price of the product per unit, is carried out on the basis of experience while running the business, so there is no optimal way to determine it. With this condition, the company's profit needs to be reviewed whether it is optimal or not. The purpose of this research is to determine the number of production units of each type of chips, in order to obtain maximum profit and also determine the efficiency that occurs in the utilization of cost and time resources. Data collection was carried out by observation and interviews. The mathematical model of the research problem is a linear program problem with three variables that can be solved by the simplex method. From the results of data analysis, it was concluded that in order to obtain maximum profit, the company had to produce 74 units of Banana Chips, 161 units of Cassava Chips and Tempe Chips not to be produced. Maximum profit is Rp. 285,387, - (previously Rp. 247,000, -), Production Capital was reduced to Rp. 889,613, - (previously Rp. 928,000, -), while the total available time was used up.
\end{abstract}

Keywords: Maximizing Profits, Many Production Units, Simplex Method. 


\section{PENDAHULUAN}

Sebuah perusahaan beserta seluruh sumber daya yang dimilikinya seperti tenaga, waktu, uang dan lainnya, agar dapat mencapai pertumbuhan yang nyata maka diperlukan pengelolaan secara profesional, dengan tujuan untuk memperoleh keuntungan yang maksimal sementara penggunaan sumber daya (modal produksi) yang minimal. Hal ini tidak lain merupakan salah satu permasalahan optimalisasi dalam riset operasi (operation research) [1].

Beberapa batasan dan asumsi dalam penelitian ini adalah jumlah total unit produksi ketiga jenis kripik paling besar sama dengan jumlah total unit produksi sebelum penelitian, total waktu produksi paling besar sama dengan total waktu produksi sebelum penelitian, modal produksi paling banyak sama dengan modal produksi sebelum penelitian, hasil perhitungan nilai keuntungan maksimum akan bisa tercapai dengan asumsi semua produk habis terjual. Hasil penelitian ini diharapkan dapat memberikan manfaat, masukan dan saran khususnya bagi pemilik perusahaan dalam pengambilan keputusan untuk melakukan perubahan komposisi banyak unit produk untuk tiap jenis kripik, agar memperoleh keuntungan maksimal.

Permasalahan yang dihadapi perusahaan ini merupakan Linear Programming Problem (LPP) atau permasalahan program linear. Karena permasalahannya terdiri dari 3 variabel keputusan maka metode simpleks dalam program linear merupakan metode yang tepat untuk memecahkan permasalahan yang dialami perusahaan, dengan cara merekomposisi banyak unit produk yang dihasilkan berdasarkan keterbatasan sumber daya yang tersedia, dengan tujuan memperoleh keuntungan yang maksimal [2]. Program linear merupakan sebuah metode matematis yang berkarakteristik linear untuk menemukan suatu penyelesaian optimal dengan cara memaksimumkan atau meminimumkan fungsi tujuan terhadap susunan kendala [3]. Program Linear merupakan salah satu metode optimasi untuk menemukan nilai optimum dari fungsi tujuan linear yang memenuhi kondisi pembatasan-pembatasan (constraints) melalui penentuan kombinasi optimal dari nilai-nilai variabel keputusan [4], [6].

Pemrograman linear adalah teknik pengoptimalan yang digunakan untuk mendapatkan solusi paling optimal untuk masalah dunia nyata. Ada dua metode untuk menyelesaikan masalah pemrograman linear yakni metode grafis dan metode simpleks. Metode simpleks menyediakan cara sistematis untuk memeriksa titiktitik simpul dari area yang layak (feasible region) untuk menentukan nilai optimal dari fungsi tujuan. Fungsi "linprog" di MatLab dapat digunakan untuk memecahkan masalah pemrograman linear [15]. Salah satu metode yang dapat dipakai untuk menyelesaikan LPP adalah Algoritma Simpleks dalam Program Linear [13].

Metode simpleks adalah metode yang paling populer dan sukses untuk menyelesaikan program linear. Fungsi tujuan dari masalah program linear (LPP) melibatkan masalah maksimisasi dan minimisasi dengan himpunan persamaan linear dan kendala pertidaksamaan. Ada beberapa metode berbeda untuk menyelesaikan LPP, seperti metode simpleks, dual-simpleks, Big-M dan dua fase [14]. Metode simpleks merupakan salah satu metode untuk menyelesaikan LPP dengan langkah mencari penyelesaian yang layak, dan menggunakan prosedur iteratif, mengembangkan pemecahan hingga dihasilkan penyelesaian yang optimal. Metode simpleks lebih efisien serta dilengkapi dengan suatu "test criteria" yang bisa memberitahukan kapan penghitungan harus dihentikan dan kapan harus dilanjutkan sampai diperoleh suatu "optimal solution" [5]. Metode simpleks pada dasarnya menggunakan prinsip solusi matriks. Penyelesaian dengan metode simpleks langkahnya adalah sebagai berikut, (1) menetapkan identifikasi variabel keputusan; (2) menetapkan identifikasi fungsi tujuan dan fungsi kendala; (3) menyusun model matematika dari LPP; (4) menetapkan titik optimal, dengan menjalankan prosedur iterasi [11].

Berikut adalah beberapa penelitian terkait dengan penerapan metode simpleks untuk tujuan optimalisasi dalam penyelesaian LPP, M.S. Rumetna, Otniel, F. Litaay, C. Sibarani, R. Tahrin, T.N. Lina, dan R.R. Pakpahan (2020) melakukan penelitian dengan judul "Optimasi Pendapatan Pembuatan Spanduk dan Baliho Menggunakan Metode Simpleks (Studi Kasus: Usaha Percetakan Shiau Printing)", dari hasil analisis disebutkan bahwa Percetakan Shiau Printing bisa memperoleh keuntungan maksimal Rp. 15.000.000,- setiap bulan [8]. E. Fardiana (2012) melakukan penelitian dengan judul "Maksimalisasi Keuntungan pada Toko Kue Martabak Doni dengan Metode Simpleks", hasil analisis datanya adalah dengan kombinasi input optimal yang diperoleh, akan memberikan keuntungan maksimal Rp. 106.817,- [7]. Budiyanto, S. Mujiharjo dan S.Umroh (2017) melakukan penelitian dengan judul "Maksimalisasi Profit Pada Perusahaan Roti Bunda Bakery Menggunakan Metode Simplek" hasil penelitiannya adalah dengan pengoptimalan pemanfaatan sumber daya, akan dapat meningkatkan keuntungan dari Rp. 1.663.914,- per minggu menjadi Rp. 2.286.049,- per minggu [9]. Akram, A. Sahari, dan A.I. Jaya (2016) melakukan penelitian dengan judul "Optimalisasi Produksi Roti Dengan Menggunakan Metode Branch And Bound" 
Metode Branch And Bound merupakan teknik penyelesaian yang dapat digunakan tidak hanya pada LPP, tapi bisa diterapkan untuk berbagai macam permasalahan yang berbeda. Metode ini penggunaannya bersamasama dengan metode simpleks [10].

Penelitian ini dilakukan pada industri rumahan (home industry) "Nanda Jaya", yang kesehariannya memproduksi Kripik Pisang, Kripik Singkong, dan Kripik Tempe. Perusahaan ini melakukan proses produksi setiap hari dengan volume produksi yang tetap, dan ongkos produksi juga relatif tetap. Komposisi banyak unit untuk tiap jenis kripik yang diproduksi, dan harga jual produk per unit, ditentukan atas dasar pengalaman selama menjalankan usahanya, jadi belum ada suatu cara yang optimal. Berdasarkan kondisi ini, untuk memperoleh keuntungan yang maksimal perusahaan menghadapi permasalahan, bagaimanakah cara menentukan banyak unit (pack) Kripik Pisang, Kripik Singkong, dan Kripik Tempe yang harus diproduksi dengan tetap memperhatikan keterbatasan sumber daya yang tersedia, agar keuntungan maksimal bisa tercapai.

Tujuan dari penelitian ini adalah membantu menyelesaikan permasalahan yang dihadapi perusahaan, dengan melakukan pembahasan tentang penentuan banyak unit Kripik Pisang, Kripik Singkong, dan Kripik Tempe yang harus diproduksi agar keuntungannya maksimal, penghitungan nilai keuntungan maksimal dalam satu periode waktu produksi, penghitungan efisiensi (penurunan) penggunaan sumber daya yang dibatasi, yakni modal produksi dan waktu produksi.

\section{METODE PENELITIAN}

\subsection{Kerangka Pemikiran}

Tahapan dalam proses penyelesaian permasalahan penelitian ini terdiri dari:

1. Identifikasi variabel penelitian, fungsi keuntungan, dan fungsi pembatas,

2. Menyusun permasalahan ke dalam model matematika, dalam hal ini bentuk pemodelan program linear,

3. Mengubah model matematika tersebut kedalam tabel simpleks,

4. Melakukan proses penyelesaian secara iteratif dengan algoritma dalam metode simpleks, hingga diperoleh tabel optimal,

5. Menyajikan penyelesaian optimal dalam bahasa matematika,

6. Melakukan interpretasi penyelesaian optimal dari permasalahan penelitian.

\subsection{Prosedur Pengumpulan Data}

Pengumpulan data dilakukan dengan observasi langsung ke lokasi dan wawancara, yang dibagi dalam dua tahap, sebagai berikut:

1. Observasi pendahuluan, tahap ini dilakukan untuk melihat langsung kondisi secara umum dari perusahaan, dan memberitahukan tujuan penelitian kepada pemilik perusahaan, agar pihak perusahaan memahami kegunaan dari hasil penelitian nantinya, disamping itu pada tahap pendahuluan ini peneliti bisa berpesan untuk menyiapkan data-data terkait dengan data-data yang dibutuhkan dalam penelitian,

2. Pengambilan data, pada tahap ini dilakukan wawancara dan klarifikasi terhadap data-data yang telah disiapkan pemilik, dengan harapan informasi yang detail dan mendalam bisa diperoleh, terkait dengan rencana analisis yang akan dilakukan.

\subsection{Teknik Analisis Data}

\section{Mendeskripsikan Data.}

Dalam langkah ini dilakukan proses transformasi dari data mentah hasil wawancara, yang berupa semua material dan sumber daya yang dibutuhkan dalam proses produksi, ke dalam bentuk data yang siap untuk melakukan pemodelan matematiknya.

\section{Identifikasi Variabel :}

Variabel keputusan : $\quad X_{1}=$ Banyak unit Kripik Pisang yang harus diproduksi

$X_{2}=$ Banyak unit Kripik Singkong yang harus diproduksi

$X_{3}=$ Banyak unit Kripik Tempe yang harus diproduksi

\section{Kendala-kendala}


Total Unit Produksi $: a_{11} X_{1}+a_{12} X_{2}+a_{13} X_{3} \leq b_{1}\left(\mathrm{a}_{\mathrm{ij}}=1\right.$, untuk setiap $\left.i \operatorname{dan} j\right)$

Total biaya $\quad: \quad a_{21} X_{1}+a_{22} X_{2}+a_{23} X_{3} \leq b_{2}$

Total waktu $\quad: \quad a_{31} X_{1}+a_{32} X_{2}+a_{33} X_{3} \leq b_{3}$

Fungsi Keuntungan $\quad Z=c_{1} X_{1}+c_{2} X_{2}+c_{3} X_{3}$

Model matematika dari permasalahan penelitian secara umum:

Menentukan $X_{1}, X_{2}$, dan $X_{3}$ dengan kendala-kendala:

$$
\begin{aligned}
& a_{11} X_{1}+a_{12} X_{2}+a_{13} X_{3} \leq b_{1}\left(\mathrm{a}_{\mathrm{ij}}=1, \text { untuk setiap } \mathrm{i} \text { dan } \mathrm{j}\right) \\
& a_{21} X_{1}+a_{22} X_{2}+a_{23} X_{3} \leq b_{2} \\
& a_{31} X_{1}+a_{32} X_{2}+a_{33} X_{3} \leq b_{3}
\end{aligned}
$$

sehingga nilai-nilai $X_{1}, X_{2}$, dan $X_{3}$ yang diperoleh akan memaksimalkan fungsi keuntungan $Z=c_{1} X_{1}+$ $c_{2} X_{2}+c_{3} X_{3}$. Selanjutnya model matematika ini akan diselesaikan dengan metode simpleks.

Untuk menyelesaikan LPP dengan metode simpleks dalam kasus memaksimalkan, model matematika dari LPP dinyatakan dalam bentuk linear sebagai berikut:

Menentukan $X=\left[X_{i}, i=1,2,3, \ldots, n\right]$

Yang memenuhi kendala : $A_{m \times n} X_{n \times 1}(\leq,=) B_{m \times 1}$

Mengoptimalkan $\left[Z_{1 \times 1}=C_{1 \times n} X_{n \times 1}\right]$.

Berikut adalah langkah-langkah menyelesaikan LPP untuk kasus memaksimumkan fungsi tujuan dalam metode simpleks:

1. Mengubah semua kendala ke bentuk kanonik dengan menambahkan peubah (variable) Slack s. Peubahpeubah slack yang ada ditambahkan ke dalam fungsi sasaran dan diberi koefisien 0 , Langkah 1 menyebabkan matriks A menjadi berukuran $\mathrm{m} \times(\mathrm{n}+\mathrm{m})$ dan memuat matriks identitas berordo $\mathrm{m}$. Lanjutkan dengan menyusun tabel awal simpleks,

2. Menentukan kolom kunci yaitu menentukan peubah yang masuk menjadi peubah basis yang baru. Kolom j adalah kolom kunci $\leftrightarrow\left(Z_{j}-C_{j}\right)>0$ terkecil,

3. Menentukan baris kunci yaitu menentukan peubah basis lama yang harus keluar digantikan oleh peubah basis yang baru. Baris i adalah baris kunci $\leftrightarrow$ indeks i $>0$, terkecil,

4. $a_{i j}$ disebut elemen kunci, lakukan operasi baris : baris i baru $=$ baris i lama $/ a_{i j}$,

5. Lakukan operasi baris pada baris yang lain sehingga elemen-elemen yang sekolom dengan elemen kunci menjadi 0 ,

6. Tabel sudah optimal $\leftrightarrow$ untuk semua j nilai $\left(Z_{j}-C_{j}\right)>0$,

7. Jika tabel belum optimal kembali ke langkah 2. [12].

Untuk menghindari analisis data dengan proses iterasi yang mungkin panjang, dalam penelitian ini digunakan perangkat lunak POM QM for Windows Versi 5.3 untuk membantu menyelesaian permasalahan penelitian.

\section{HASIL DAN PEMBAHASAN}

\subsection{Deskripsi Data}

Berikut ini adalah deskripsi data pada kondisi awal dari industri rumahan "Nanda Jaya" yang telah dibuat secara detil dan teliti. Deskripsi data ini dibuat dalam satu periode waktu produksi yakni sehari, dan disajikan dalam Tabel 1, berikut: 
Tabel 1. Deskrisi data hasil pengamatan.

\begin{tabular}{|c|c|c|c|c|c|c|c|c|c|}
\hline No & $\begin{array}{c}\text { Jenis } \\
\text { Kripik }\end{array}$ & $\begin{array}{l}\text { Produksi } \\
\quad \text { (unit) }\end{array}$ & $\begin{array}{c}\text { Total } \\
\text { Biaya } \\
\text { (Rp.) }\end{array}$ & $\begin{array}{c}\text { Total } \\
\text { Waktu } \\
\text { (menit) }\end{array}$ & $\begin{array}{c}\text { Beaya } \\
\text { / Unit } \\
\text { (Rp.) }\end{array}$ & $\begin{array}{l}\text { Jual/ } \\
\text { Unit } \\
\text { (Rp.) }\end{array}$ & $\begin{array}{c}\text { Waktu/ } \\
\text { Unit } \\
\text { (menit) }\end{array}$ & $\begin{array}{c}\text { Total } \\
\text { Jual } \\
\text { (Rp.) } \\
\end{array}$ & $\begin{array}{l}\text { Laba } \\
\text { /Unit } \\
\text { (Rp.) }\end{array}$ \\
\hline 1 & Pisang & 120 & 468.000 & 370 & 3.900 & 5.000 & 3,1 & 600.000 & 1.100 \\
\hline 2 & & 75 & 280.000 & 280 & 3.733 & 5.000 & 3,7 & 375.000 & 1.267 \\
\hline & Tempe & 40 & 180.000 & 175 & 4.500 & 5.000 & 4,4 & 200.000 & 500 \\
\hline & Total & 235 & 928.000 & 825 & - & - & - & 1.175 .000 & \\
\hline
\end{tabular}

Sumber : Industri rumahan "Nanda Jaya"

Dari Tabel 1 diperoleh keuntungan awal = Rp. 1.175.000 - Rp. $928.000=$ Rp. 247.000,-.

\subsection{Penyusunan Model Matematika}

Menentukan $X_{1}, X_{2}$, dan $X_{3}$ dengan kendala-kendala:

Total Unit Produksi

Total biaya

Total waktu

$$
\begin{aligned}
& X_{1}+X_{2}+X_{3} \leq 235 \\
& 3.900 X_{1}+3.733 X_{2}+4.500 X_{3} \leq 928.000 \\
& 3,1 \quad X_{1}+3,7 \quad X_{2}+4,4 \quad X_{3} \leq 825 \\
& X_{1}, X_{2}, X_{3} \geq 0
\end{aligned}
$$

sehingga nilai-nilai $X_{1}, X_{2}$, dan $X_{3}$ yang diperoleh akan memaksimalkan, fungsi keuntungan

$$
Z=1.100 X_{1}+1.267 X_{2}+500 X_{3}
$$

Selanjutnya disusun tabel awal simpleks, dengan mengubah semua fungsi kendala dalam bentuk implisit, dengan menambahkan slack variable $S_{1}, S_{2}$, dan $S_{3}$

$\begin{aligned} X_{1}+X_{2}+X_{3}+S_{1} & =235 \\ 3.900 X_{1}+3.733 X_{2}+4.500 X_{3}+S_{2} & =928.000 \\ 3,1 X_{1}+3,7 X_{2}+4,4 X_{3} & +S_{3}=825 \\ X_{1}, X_{2}, X_{3}, S_{1}, S_{2}, S_{3} & \end{aligned}$

Bentuk implisit dari fungsi keuntungan:

$$
Z-1.100 X_{1}-1.267 X_{2}-500 X_{3}=0
$$

Tabel 2. Tabel Awal Simpleks

\begin{tabular}{crrrrrrr}
\hline Basis & \multicolumn{1}{c}{$\mathbf{X}_{\mathbf{1}}$} & \multicolumn{1}{c}{$\mathbf{X}_{\mathbf{2}}$} & $\mathbf{X}_{\mathbf{3}}$ & $\mathbf{S}_{\mathbf{1}}$ & $\mathbf{S}_{\mathbf{2}}$ & \multicolumn{1}{c}{$\mathbf{S}_{\mathbf{3}}$} & \multicolumn{1}{c}{$\mathbf{H}$} \\
\hline $\mathbf{S}_{\mathbf{1}}$ & 1 & 1 & 1 & 1 & 0 & 0 & 235 \\
\hline $\mathbf{S}_{\mathbf{2}}$ & 3.900 & 3.733 & 4.500 & 0 & 1 & 0 & 928.000 \\
\hline $\mathbf{S}_{\mathbf{3}}$ & 3,1 & 3,7 & 4,4 & 0 & 0 & 1 & 825 \\
\hline $\mathbf{Z}$ & -1.100 & -1.267 & -500 & 0 & 0 & 0 & 0 \\
\hline
\end{tabular}

Input data permasalahan penelitian ke dalam POM QM, ditunjukkan dalam Tabel 3 berikut:

Tabel 3. Input Data

\begin{tabular}{lrrrrrl}
\hline & X1 & X2 & X3 & & RHS & \multicolumn{1}{c}{ Equation form } \\
\hline Maximize & 1100 & 1267 & 500 & & & Max 1100X1+ 1267X2+ 500X3 \\
\hline Banyak unit & 1 & 1 & 1 & $<$ & 235 & X1 1 X2 + X3 $<=235$ \\
\hline $\begin{array}{l}\text { Biaya } \\
\text { Prod./unit }\end{array}$ & 3900 & 3733 & 4500 & $<=$ & 928000 & $3900 X 1+3733 \mathrm{X} 2+4500 \mathrm{X} 3<=928000$ \\
\hline $\begin{array}{l}\text { Waktu } \\
\text { Prod./unit }\end{array}$ & 3.1 & 3.7 & 4.4 & $<$ & 825 & $3.1 \mathrm{X} 1+3.7 \mathrm{X} 2+4.4 \mathrm{X} 3<=825$ \\
\hline
\end{tabular}

Pada Tabel 4 menunjukkan proses iterasi dari kondisi awal hingga kondisi optimal. 
Tabel 4. Proses iterasi (iteration)

\begin{tabular}{|c|c|c|c|c|c|c|c|c|}
\hline $\mathbf{C}_{\mathbf{j}}$ & $\begin{array}{r}\text { Basic } \\
\text { Var. }\end{array}$ & Quantity & $\begin{array}{c}1100 \\
\mathrm{X} 1 \\
\end{array}$ & $\begin{array}{c}1267 \\
\times 2 \\
\end{array}$ & $\begin{array}{l}500 \\
\times 3 \\
\end{array}$ & $\begin{array}{c}0 \\
\text { slack } 1\end{array}$ & $\begin{array}{c}0 \\
\text { slack } 2 \\
\end{array}$ & $\begin{array}{c}\mathbf{0} \\
\text { slak 3 } \\
\end{array}$ \\
\hline \multicolumn{9}{|c|}{ Iteration 1} \\
\hline $\mathbf{0}$ & slack 1 & 235 & 1 & 1 & 1 & 1 & 0 & 0 \\
\hline $\mathbf{0}$ & slack 2 & 928,000 & 3,900 & 3,733 & 4,500 & 0 & 1 & 0 \\
\hline \multirow[t]{3}{*}{$\mathbf{0}$} & slack 3 & 825 & 3.1 & 3.7 & 4.4 & 0 & 0 & 1 \\
\hline & $\mathrm{zj}$ & 0 & 0 & 0 & 0 & 0 & 0 & 0 \\
\hline & $c j-z j$ & & 1,100 & 1,267 & 500 & 0 & 0 & 0 \\
\hline \multicolumn{9}{|c|}{ Iteration 2} \\
\hline $\mathbf{0}$ & slack 1 & 12.027 & 0.1622 & 0 & -0.19 & 1 & 0 & -0.27 \\
\hline $\mathbf{0}$ & slack 2 & $95,641.90$ & 772.35 & 0 & 60.76 & 0 & 1 & $-1,01$ \\
\hline \multirow[t]{3}{*}{1267} & $\mathrm{X} 2$ & 222.97 & 0.8378 & 1 & 1.19 & 0 & & 0.27 \\
\hline & $\mathrm{zj}$ & $282,506.75$ & 1061.54 & 1267 & 1506.7 & 0 & & 0342.43 \\
\hline & $c j-z j$ & & 38.4595 & 0 & $-1,006.7$ & 0 & & $0-342.43$ \\
\hline \multicolumn{9}{|c|}{ Iteration 3} \\
\hline 1100 & $\mathrm{X} 1$ & 74.17 & 1 & 0 & -1.17 & 6.17 & & $0 \quad-1.67$ \\
\hline $\mathbf{0}$ & slack 2 & 38,359 & 0 & 0 & 961.83 & $-4,76$ & & 1278.33 \\
\hline \multirow[t]{3}{*}{1267} & $\mathrm{X} 2$ & 160.83 & 0 & 1 & 2.17 & -5.17 & 0 & 1.67 \\
\hline & $\mathrm{zj}$ & 285,359 & 1100 & 1267 & 1461.83 & 237.17 & & 0278.33 \\
\hline & $c j-z j$ & & 0 & 0 & -961.83 & -237.17 & & $0-278.33$ \\
\hline
\end{tabular}

Pada Tabel 5 merupakan penyajian penyelesian optimal dari LPP.

Tabel 5. Linear Programming Result

\begin{tabular}{lrrrrrr}
\hline & \multicolumn{1}{c}{ X1 } & \multicolumn{1}{c}{ X2 } & \multicolumn{1}{c}{ X3 } & & \multicolumn{1}{c}{ RHS } & \multicolumn{1}{c}{ DUAL } \\
\hline Maximize & 1100 & 1267 & 500 & & & \\
\hline Banyak unit & 1 & 1 & 1 & $<=$ & 235 & 237.17 \\
\hline Biaya Prod./unit & 3900 & 3733 & 4500 & $<=$ & 928000 & 0 \\
\hline Waktu Prod. /unit & 3.1 & 3.7 & 4.4 & $<=$ & 825 & 278.33 \\
\hline Solution & 74.17 & 160.83 & 0 & & 285359.2 & \\
\hline
\end{tabular}

Rincian penyelesaian optimal LPP disajikan dalan Tabel 6 berikut:

Tabel 6. Solution list

\begin{tabular}{llr}
\hline \multicolumn{1}{c}{ Variable } & \multicolumn{1}{c}{ Status } & \multicolumn{1}{c}{ Value } \\
\hline X1 & Basic & 74.17 \\
\hline X2 & Basic & 160.83 \\
\hline X3 & NONBasic & 0 \\
\hline slack 1 & NONBasic & 0 \\
\hline slack 2 & Basic & 38359.2 \\
\hline slack 3 & NONBasic & 0 \\
\hline Optimal Value $(Z)$ & & 285359.2 \\
\hline
\end{tabular}

\subsection{Interpretasi Hasil Analisis Data}

Tabel 4 merupakan proses iterasi dari tabel simpleks awal (Tabel. 2) hingga diperoleh tabel optimal (Tabel 5) yang menggambarkan kondisi optimal dengan harga-harga variabel yang telah diperoleh.

Dari Tabel 5 yang menggambarkan solusi permasalahan program linear, terlihat bahwa nilai keuntungan harian maksimal yang bisa dicapai adalah Rp. 285.359,2, tercapai pada kondisi $\mathrm{X}_{1}=74,17$ (dibulatkan 74), $X_{2}=160,83$ (dibulatkan 161) dan $X_{3}=0$. Ini berarti bahwa untuk memperoleh keuntungan maksimal, maka perusahaan harus memproduksi kripik pisang sebanyak 74 unit dan kripik singkong sebanyak 161 unit, dengan keuntungan maksimal sebesar:

$$
\mathrm{Z}_{\max }=1.100(74)+1.267(161)+500(0)=285.387
$$

Biaya Produksi Optimal $=3.900(74)+3.733(161)=$ Rp. 889.613,- (terjadi penurunan biaya produksi sebesar 928.000-889.613 = Rp. 38.387). Nilai penurunan biaya ini ditunjukkan juga dari tabel 6 . yaitu nilai variabel slack 2 sebesar Rp. 38.359,2 (beda nilai akibat pembulatan), nilai variabel slack 3 adalah 0 , ini menunjukkan bahwa total waktu yang tersedia habis dipakai untuk melakukan proses produksi yang baru. 
Secara ringkas efisiensi yang diperoleh perusahaan, setelah analisis data disajikan dalam Tabel 7 berikut.

Tabel 7. Efisiensi hasil penelitian

\begin{tabular}{lllr}
\hline & KONDISI AWAL & KONDISI AKHIR & \multicolumn{1}{c}{ EFISIENSI } \\
\hline & 120 unit K. Pisang & 74 unit K. Pisang & \\
PRODUKSI & $\begin{array}{l}\text { 75 unit K. Singkong } \\
\text { 40 unit K. Tempe }\end{array}$ & & \\
& 928.000 & 889.613 & 38.387 \\
\hline BIAYA PROD. (Rp.) & 825 & 825 & 0 \\
\hline WAKTU (menit) & 247.000 & 285.387 & 38.387 \\
\hline KEUNTUNGAN (Rp.) & & &
\end{tabular}

\section{KESIMPULAN}

Dari hasil analisis data perusahaan, dapat disampaikan beberapa kesimpulan berikut:

1. Untuk bisa mencapai keuntungan maksimal, perusahaan harus memproduksi 74 unit Kripik Pisang dan 161 unit Kripik Singkong,

2. Keuntungan maksimal yang diperoleh dalam sehari sebesar Rp. 285.387,-

3. Dalam kondisi optimal, total biaya produksi turun menjadi Rp. 889.613,-- (semula Rp. 928.000,-) terjadi efisiensi sebesar Rp. 38.387,- waktu produksi yang dibutuhkan sama dengan waktu produksi sebelum penelitian, yakni selama 825 menit.

\section{DAFTAR PUSTAKA}

[1] T. Chandra, "Penerapan Algoritma Simpleks dalam Aplikasi Penyelesaian Masalah Program Linear," Jurnal TIMES, vol. IV, no. 1, pp. 18-21, 2015.

[2] S. Christian, "Penerapan Linear Programming untuk Mengoptimalkan Jumlah Produksi dalam Memperoleh Keuntungan Maksimal pada CV Cipta Unggul Manunggal," Journal The WINNERS, vol. 14, no. 1, pp. 55-60, 2013.

[3] Y. Budiasih, "Maksimalisasi Keuntungan dengan Pendekatan Metode Simpleks Kasus pada Pabrik Sosis SM," Jurnal Liquidity, vol. 2, no. 1, pp. 59-65, 2013.

[4] T.N. Lina, B.S. Marlissa, M.S. Rumetna, dan J.E. Lopulalan, "Penerapan Metode Simpleks untuk Meningkatkan Keuntungan Produksi," JURIKOM (Jurnal Riset Komputer), vol. 7, no. 3, pp. 459-468, 2020.

[5] Z. Nasution, H. Sunandar, I. Lubis, dan L.T. Sianturi, "Penerapan Metode Simpleks untuk Menganalisa Persamaan Linear dalam Menghitung Keuntungan Maksimum” JURIKOM (Jurnal Riset Komputer), vol. 3, no. 4, pp. 42-48, 2016.

[6] M.R. Aulia, D.N. Putra, S. Murniati, Mustahiroh, D. Oktavia, dan Y. Budiasih, "Maksimalisasi Keuntungan dengan Pendekatan Metode Simpleks Studi Kasus pada Pabrik Sendal X di Ciputat, Tangerang Selatan,” Jurnal Liquidity, vol. 2, no. 2, pp. 144-150, 2013.

[7] E. Fardiana, "Maksimalisasi Keuntungan pada Toko Kue Martabak Doni dengan Metode Simpleks," UG Jurnal, vol. 6, no. 09, pp. 11-14, 2012.

[8] M.S. Rumetna, Otniel, F. Litaay, C. Sibarani, R. Tahrin, T.N. Lina, dan R.R. Pakpahan, "Optimasi Pendapatan Pembuatan Spanduk dan Baliho Menggunakan Metode Simpleks (Studi Kasus : Usaha Percetakan Shiau Printing)," Jurnal Jurikom, vol. 7, no. 2, pp. 278-284, 2020.

[9] Budiyanto, S. Mujiharjo, dan S. Umroh, "Maksimalisasi Profit pada Perusahaan Roti Bunda Bakery Menggunakan Metode Simpleks," Jurnal Agroindustri, vol. 7, no. 2, pp. 84-98, 2017.

[10] Akram, A. Sahari, dan A.I. Jaya, "Optimalisasi Produksi Roti dengan Metode Branch and Bound," JIMT (Jurnal Ilmiah Matematika dan Terapan), vol. 13, no. 2, pp. 98-107, 2016.

[11] E.T. Susdarwono, "Pemrograman Linear Permasalahan Ekonomi Pertahanan : Metode Grafik dan Metode Simpleks," Jurnal Teorema (Teori dab Riset Matematika\} vol. 5, no. 1, pp. 89-104, 2020.

[12] P. Sriwasito, B. Surarso, dan E.A. Sarwoko, "Sistem Aplikasi Penyelesaian Masalah Program Linear Standar Maksimal Berbasis Web dengan Keluaran Sesuai Produk Kemasan terkecil," JSINBIS (Jurnal Sistem Informasi Bisnis), vol. 1, no. 2, pp. 99-107, 2011.

[13] Sukanta, and A.I. Ramadhan, "Simplex Method Linear Program Application In Process Of Transition To Reduce Use Of Products In Polyster Material In Indonesia," International Journal Of Scientific \& Technology Research (IJSTR), vol. 5, no. 09, pp. 106-110, 2016.

[14] M.R. Hussain, M. Qayyum, and M.E. Hussain, "Effect of Seven Steps Approach on Simplex Method to Optimize the Mathematical Manipulation," International Journal of Recent Technology and Engineering (IJRTE), vol. 7, no. 2, pp. 34-43, 2019. 
[15] A. Velinov, and V. Gicev , "Practical Application of Simplex Method for Solving Linear Programming Problem," Balkan Journal of Applied Mathematics and Informatics (BJAMI), vol. 1, no. 1, pp. 7-15, 2018. 
